has been variously estimated at between two and six prism dioptres. Greater amounts than this do not necessarily imply deficient convergence; in the absence of good convergence power symptoms. of discomfort may, however; arise. (The author, in hypermetropic enjoyment of full binocular vision, is not inconvenienced by sixteen dioptres of near point exophoria, with one dioptre of hyperphoria.)

Little attempt is made here to indicate the use to which an examiner may put the information obtained. Familiarity with the language and customs of strangers gives mutual benefit by dispelling distrust and misunderstanding; with. a wider knowledge of euphoropsia and the factors that disturb it, an ophthalomogist will make his own judgment, critical and reasoned, of the relative values of prismatic spectacles, prism exercises, and the services of the trained orthoptist. All these have suffered some unwarranted neglect in the past from a fear which is bred out of ignorance by suspicion. It is the misfortune of orthoptists to have been associated primarily with the training of squinting children. The spectacular successes sometimes achieved in suitable cases led at first to indiscriminate reference of unsuitable ones, and inevitable disappointment. We do not yet sufficiently appreciate the extent to which they can help selected adult patients by " eye exercises" of the right kind.

\title{
TRANSIENT SLIT-LAMP APPEARANCES DUE TO CONCUSSION BY SMALL PARTICLES*
}

BY

\author{
Major D. D. STENhouSE STEWART, R.A.M.C. and \\ Major J. P.F. LLoYd, R.A.M.C.
}

WHEN a "back-fire" occurs from the breech of a service rifle, a part of the exploding gases escapes backwards conveying with it very small particles of foreign matter, mainly fragments of incompletely burnt charge. These impinge upon the right side of the face of the soldier firing the rifle; though the force is considerable, the depth of penetration of skin, conjunctiva, or cornea, is slight owing to the small mass of each particle.

A soldier received an injury of this kind at about two o'clock one afternoon. He was admitted to a Military Hospital the same evening. His face and eye were cleaned superficially, and he was examined more thoroughly the following morning. By slit-lamp microscopy multiple minute foreign bodies of various sizes were

* Received for publication, July 5, 1943. 
seen very superficially embedded in the right cornea, and there were many scattered areas of endothelial bedewing. A feature of unusual interest was the appearance at the Descemeto-endothelial level, of minute grey plaques disposed somewhat in the manner of the leaves of a formal laurel wreath, the central area being clear. The plaques of which the wreath was formed gave the appearance of a greyish-white substance (? oedema) distributed around the

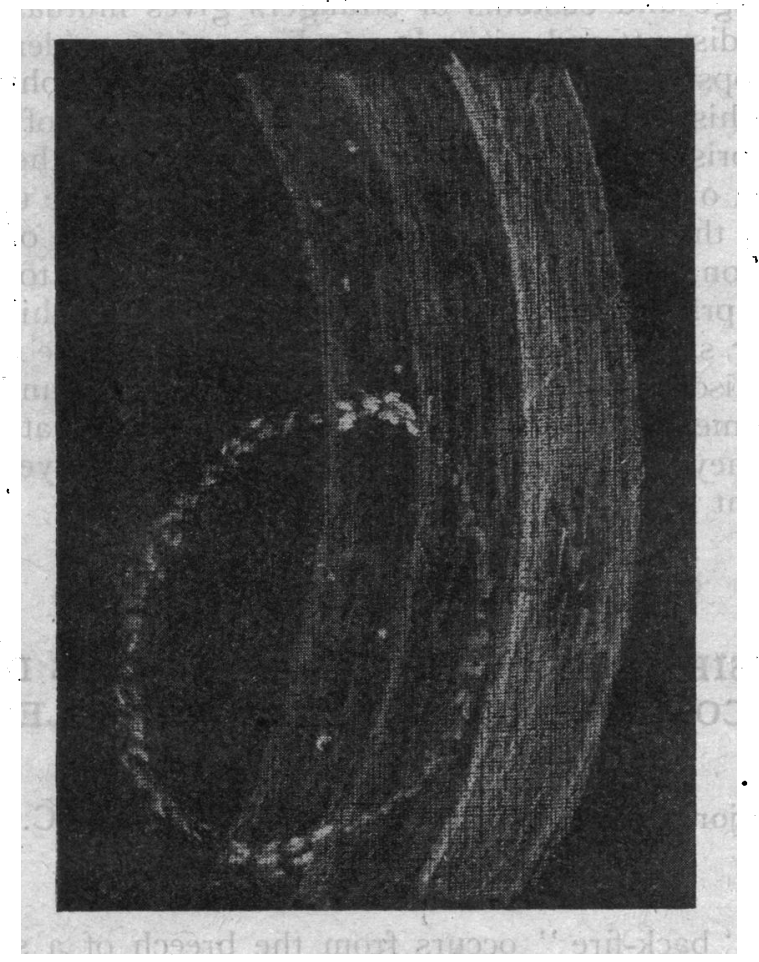

endothelial cells in the same location as the pigment of a Krukenburg's spindle. With 'few peripheral exceptions, these "wreaths" were circular and of an average diameter of about $2 \mathrm{~mm}$., some slightly larger, some a little less, a superficial foreign body being seen to correspond to the centre of each wreath. The wreaths did not intersect and were not cotangential in any instance. The phenomenon was still present 30 hours after the injury, but no trace could be found 15 hours later.

The more superficial foreign bodies were subsequently removed, several minute deep ones being left as their removal would cause more damage than is likely to arise from their retention. The eye was entirely quiet a week after the injury, the man's visual 


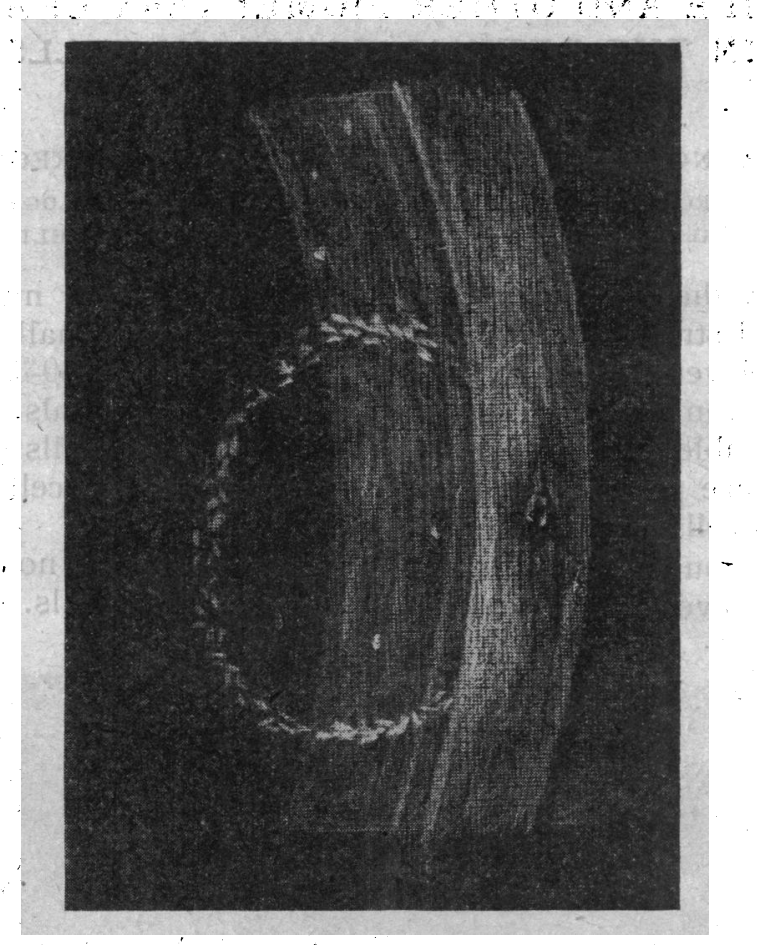

acuity, then, as formerly, being E.E. unaided $6 / 36$; with glasses $6 / 6$.

It is suggested that the grey flecks of which the " wreaths." are constituted (like those transient superficial epithelial grey marks seen in association with a bland conjunctival foreign body) are optical effects ftom local variation of index of refraction.

The disturbance giving, rise to the change in this case is inter, preted as the production of general internal stresses in the cornea by the pressure of the exploded gases, to which is added a spherical concussion wave of some definite frequency (possibly of high intensity though brief duration) radiating from the point of impact of each foreign body. "It is believed that these "wreaths" of almost uniform diameter could arise from maximum disturbance at the antinode of a spherical concussion wave of this kind, superimposed on the general internal corneal stress. 